\section{Dr. Pincus, et al reply}

\section{To the Editor:}

We thank Dr. Leeb for his comments, and agree entirely with most of his points, including that speakers at educational events should present their views independently rather than a "canned" message, discuss their own experience, and address the clinical needs of the majority of rheumatologists. Topics such as the Disease Activity Score (DAS), patient questionnaires, magnetic resonance imaging, or other measures, should be presented only by speakers who have experience with these measures.

We also agree that clinical decisions require physician judgment and should not be based on a rote implementation of a certain numerical value of the index. However, we do feel that quantitative monitoring of patients in usual clinical care enhances judgment and clinical decisions, documented in clinical trials and clinical experience.

We have attempted over the years to simplify quantitative measures for usual clinical care, including reduction of a 68 -joint count to 28 joints ${ }^{1}$, and a 20-item Health Assessment Questionnaire (HAQ) to an 8-item modified HAQ (MHAQ) $)^{2}$ or a 10 -item multidimensional HAQ (MDHAQ) ${ }^{3}$. By about 1995, we found that quantitative data from a patient questionnaire along with a careful clinical joint examination, without quantitation of the exact number of swollen and tender joints, were sufficient for informed clinical decisions and documentation of changes. We also have discussed some limitations of the DAS ${ }^{4}$.

Routine Assessment of Patient Index Data 3 (RAPID3) scores, based only on patient questionnaire data for the 3 RA Core Data Set measures patient functional status, pain, and global estimate - are correlated with DAS28 and Clinical Disease Activity Index at highly significant levels, considerably greater than correlations of erythrocyte sedimentation rate with C-reactive protein ${ }^{5}$. We suggest that RAPID 3 scores greater than 6 on a $0-30$ scale or 2 on a $0-10$ scale indicate a need to consider strongly a change in therapy, while levels below 6 on a $0-30$ scale or 2 on a $0-10$ scale indicate low activity, and below 3 on a $0-30$ scale or 1 on a $0-10$ scale indicate near-remission5. RAPID3 scores and other MDHAQ medical history information save time for patients and clinicians, document changes in status, enhance clinical decisions, and result in better outcomes ${ }^{6}$.

We also agree with Dr. Greenwald, who points out another aspect of "hotel-based medicine" - large expenditures for attractive technology that adds nothing to an educational program. Indeed, it could be suggested that if doctors in the same room were viewing each other by videocasting rather than in person, part of the pedagogical value is undoubtedly lost. The idea of a movie star might actually perk up the programmed talk.

If most rheumatologists receive 4-6 dinner invitations a month, the annual expenditures could be easily used to support a formal clinical trial of RAPID3 in enhancing patient outcomes and documentation, analogous to studies using American College of Rheumatology criteria and DAS28 to maintain "tight control" of patients with $\mathrm{RA}^{7}$, such as FIN-RACo ${ }^{8}$, TICO$\mathrm{RA}^{9}, \mathrm{BeSt}^{10}$, and CIMESTRA ${ }^{11}$. Such a clinical trial might be considerably more valuable to the sponsors, not to mention patients and rheumatologists, than further "hotel-based medicine."

We appreciate these comments and welcome continuing dialogue, particularly toward elimination of the canned talk.

THEODORE PINCUS, MD; YUSUF YAZICI, MD, Division of Rheumatology, New York University School of Medicine and NYU Hospital for Joint Diseases, New York, New York; MARTIN J. BERGMAN, MD, Arthritis and Rheumatism, Taylor Hospital, Ridley Park, Pennsylvania, USA. Address reprint requests to Dr. T. Pincus, Division of Rheumatology, Room 1608, NYU Hospital for Joint Diseases, 301 East 17th Street, New York, NY 10003, USA.

\section{REFERENCES}

1. Fuchs HA, Brooks RH, Callahan LF, Pincus T. A simplified twenty-eight joint quantitative articular index in rheumatoid arthritis. Arthritis Rheum 1989;32:531-7.

2. Pincus T, Summey JA, Soraci SA Jr, Wallston KA, Hummon NP. Assessment of patient satisfaction in activities of daily living using a modified Stanford Health Assessment Questionnaire. Arthritis Rheum 1983;26:1346-53.

3. Pincus T, Sokka T, Kautiainen H. Further development of a physical function scale on a Multidimensional Health Assessment Questionnaire for standard care of patients with rheumatic diseases. J Rheumatol 2005;32:1432-9.

4. Pincus T. The DAS is the most specific measure, but a patient questionnaire is the most informative measure to assess rheumatoid arthritis. J Rheumatol 2006;33:834-7.

5. Pincus T, Swearingen CJ, Bergman M, Yazici Y. RAPID3 (Routine Assessment of Patient Index Data 3), a rheumatoid arthritis index without formal joint counts for routine care: Proposed severity categories compared to Disease Activity Score and Clinical Disease Activity Index categories. J Rheumatol 2008;35:2136-47. [Epub ahead of print.]

6. Sokka T, Pincus T. Improved outcomes in consecutive patients with rheumatoid arthritis in 2000 compared to 1985 , according to an identical cross sectional quantitative standard protocol to evaluate rheumatoid arthritis (SPERA) [abstract]. Arthritis Rheum 2002;46 Suppl:S242.

7. Pincus T, Gibofsky A, Weinblatt ME. Urgent care and tight control of rheumatoid arthritis as in diabetes and hypertension: better treatments but a shortage of rheumatologists. Arthritis Rheum 2002;46:851-4.

8. Puolakka K, Kautiainen H, Möttönen T, et al. Early suppression of disease activity is essential for maintenance of work capacity in patients with recent-onset rheumatoid arthritis: five-year experience from the FIN-RACo trial. Arthritis Rheum 2005;52:36-41.

9. Grigor C, Capell H, Stirling A, et al. Effect of a treatment strategy of tight control for rheumatoid arthritis (the TICORA study): a single-blind randomised controlled trial. Lancet 2004;364:263-9.

10. Goekoop-Ruiterman YPM, de Vries-Bouwstra JK, Allaart CF, et al. Comparison of treatment strategies in early rheumatoid arthritis: a randomized trial. Ann Intern Med 2007;146:406-15.

11. Hetland ML, Stengaard-Pedersen K, Junker P, et al. Aggressive combination therapy with intra-articular glucocorticoid injections and conventional disease-modifying anti-rheumatic drugs in early rheumatoid arthritis: second-year clinical and radiographic results from the CIMESTRA study. Ann Rheum Dis 2008;67:815-22.

J Rheumatol 2009;36:2; doi:10.3899/jrheum.080970 